\title{
Preparation and Properties of a Hyphal Wall Fraction from Pithomyces chartarum
}

\author{
By D. W. RUSSELL, R. J. STURGEON AND VALERIE WARD \\ Twyford Laboratories, Twyford Abbey Road, London, N.W. 10
}

(Received 28 February 1964)

\begin{abstract}
SUMMARY
A low-sporing isolate of Pithomyces chartarum was grown in submerged liquid culture in defined medium, and a hyphal wall fraction isolated by mechanical disruption. It contains about $20 \%$ protein, $40 \%$ bound hexoses, $10 \%$ bound glucosamine, $10 \%$ lipid and $5 \%$ ash.
\end{abstract}

\section{INTRODUCTION}

The chemical nature of the spicules which invest the conidia of Pithomyces chartarum was recently elucidated (Bertaud, Morice, Russell \& Taylor, 1963). Continuing such studies in chemical morphology, we wished to investigate the spore wall that underlies the layer of lipid and depsipeptide. Because comparative data about the composition of hyphal and conidial walls do not exist for any fungus, we began by investigating the hyphal walls of $P$. chartarum. We aimed to find conditions for isolating, in quantity, a hyphal wall fraction free from conidial contamination, to analyse it in terms of its total content of carbohydrate, lipid and protein, and to determine the qualitative composition of these groups of substances in terms of their monosaccharide, fatty acid and amino acid contents, respectively.

\section{METHODS}

Organism. An isolate of Pithomyces chartarum (Ellis, 1960; Dingley, 1962) found growing on debris of Holcus lanatus at Virginia Water, Surrey, in September 1961 (Lacey \& Gregory, 1962), and kindly provided by Dr P.H. Gregory, F.R.S. (Rothamsted Experimental Station, Harpenden, England) was designated isolate E. It formed moderate numbers of spores in surface culture in potato carrot broth at $25^{\circ}$, and sectored frequently on potato glucose agar. Single hyphal tips from the edges of sectors of 3-week cultures were plated to fresh agar. After five such subcultures, two out of the many isolates obtained formed very few spores. One, designated E-HT/1, was chosen for use.

Colonies of E-HT/1 grown from single hyphal tips on potato glucose agar at $25^{\circ}$ for 21 days were dark green to black on the under surface. The superficial mycelium was grey-green except for a central portion which was buff and floccose. The edges of the colonies were olive-green and adpressed. Sectoring occurred rarely and only towards the edges of the colonies. The aerial mycelium was thin-walled and almost hyaline, with frequent septa; hyphae, 2.0-4.0 $\mu$ diam. Two other types of mycelium were observed; in one type the hyphae, 2.0-3.6 $\mu$ diam., were brown, evenly septate, and appeared to bear conidia. The other type was composed of massive hyphae, 
4.0-6.6 $\mu$ diam., thick-walled, dark, and with more frequent septa. Conidia were few, brown, 9.5-15 $\mu \times 19-25 \mu$, with two or three transverse septa, and one longitudinal septum or none.

Agar discs (3 mm. diameter) cut from potato glucose agar colonies of isolate E-HT/1 were plated on to each of the five solid media listed below, and incubated for 3 weeks at $15,20,25,30$ or $37^{\circ}$. No growth occurred at $37^{\circ}$. No sectoring was seen on the minimal medium at any temperature, but on all other media sectors were observed, most abundantly on the 'complete' medium at $25^{\circ}$. No colony sectored at $15^{\circ}$. Most rapid radial extension of colonies on potato glucose agar took place at $25^{\circ}$.

Media. Potato carrot broth (Done, Mortimer, Taylor \& Russell, 1961) contained total solids $25 \mathrm{mg} . / \mathrm{ml}$., reducing sugars $20 \mathrm{mg} . / \mathrm{ml}$. (adjusted with glucose) and nitrogen $1 \mathrm{mg} . / \mathrm{ml}$. (adjusted with glycine). Ross's medium was a solution of salts, glucose and asparagine (Ross \& Thornton, 1962; Butler, Russell \& Clarke, 1962).

Five solid media were used: $(a)$ potato glucose agar (Oxo Limited, London, England); (b) potato carrot agar (Done et al. 1961); (c) the minimal medium of Pontecorvo (1953); (d) minimal medium + peptone (2 g./l.), casein hydrolysate (3 g./1.), yeast nucleic acid (0.5 g./1.) (these products were supplied by British Drug Houses Ltd., Poole, Dorset) and Yeastral (1 g./l.) (Brewer's Food Supply Co. Ltd., 189-191 Fountainbridge, Edinburgh 3); (e) Ross's medium containing agar $2 \%$ $(\mathrm{w} / \mathrm{v})$.

Media were sterilized by autoclaving at $120^{\circ}$ for $20 \mathrm{~min}$.

Fermentation vessel. The fermentor was a 5 l. glass aspirator, with a mouth $4 \cdot 0$ cm. diam., closed by a rubber bung. A glass tube fitted with a cottonwool plug passed through the bung, terminating $5 \mathrm{~cm}$. below it and serving as an outlet for gases and as a means of withdrawing samples for analysis. Two further glass tubes passing through the bung each bore at the lower end an upward-facing sintered glass disc, porosity 1, placed at about one-third of the distance from the bottom of the vessel to the surface of the medium (3.7 1.). Air from a compressor was filtered through cottonwool to remove oil mist, then sterilized by passage through a ceramic filter (Aerox Ltd., Glasgow, Scotland) and passed at about 8 l./min., first through sterile water and then through the sintered glass discs. Additional stirring was by a Teflon-covered magnet, $6 \times 1 \mathrm{~cm}$., turned at about $500 \mathrm{rev} . / \mathrm{min}$. by a magnetic rotor beneath the fermentor. Two vortices of fine air bubbles were formed in the medium, one travelling upwards and the other downwards. The fermentor was immersed in a bath at $25 \pm 0 \cdot 2^{\circ}$.

Growth of organism. To sterile water $(100 \mathrm{ml}$.) contained in a sterile stainless steel 'Atomix' blender (50-200 ml.; Measuring and Scientific Equipment Ltd., Spenser St., London, S.W. 1) were added six discs $(6 \mathrm{~mm}$. diam.) cut aseptically from a 10 day culture of isolate E-HT/ 1 on potato glucose agar grown at $25^{\circ}$. Blending was carried out for $1 \mathrm{~min}$. at half speed. A portion $(10 \mathrm{ml}$.) of the resulting suspension was added to each of three Ehrlenmeyer flasks (2 1.) containing Ross's medium $(200 \mathrm{ml}$.). The plugged flasks were incubated for $65 \mathrm{hr}$ on a 'Gyrotory' Incubator Shaker (New Brunswick Scientific Inc., P.O. Box 606, New Brunswick, N.J., U.S.A.) at $26^{\circ}$ and 250 strokes/min. The mycelial dry weight was determined in two flasks whilst the contents of the third were transferred aseptically to the 
fermentor containing sterile Ross's medium (3.5 1.). An average inoculum contained about $7 \mathrm{mg}$. dry-wt. mycelium $/ \mathrm{ml}$. The organism was incubated at $25^{\circ}$ for 4 days.

The growth in the fermentor, examined microscopically at the end of incubation, consisted of straight, hyaline hyphae, $1 \cdot 6-2 \cdot 0 \mu$ diam. and regularly septate. Some darker mycelium which formed a ring adherent to the wall of the vessel at the level of the liquid surface was discarded. In more than three dozen fermentations conidia were never observed.

Small portions of the mycelium obtained at the end of the incubation period were used as inocula for potato glucose agar plates which were incubated for 10 days at $\mathbf{2 5}^{\circ}$ and then examined for the presence of contaminants. Meanwhile, when no obvious contamination was detected by microscopic examination, the contents of the fermentor were used for the preparation of the wall fraction.

\section{Harvesting and preparation of the hyphal wall fraction}

The culture (3.5 1.) was dispersed in a Waring Blendor (Waring Products Corporation, New York, N.Y.) at 19,000 rev./min. for $45-60$ sec. at $4^{\circ}$, and then centrifuged in a pre-cooled Continuous Flow Centrifuge (Sharples Centrifuges Ltd., Camberley, Surrey, England). The mycelium was redispersed in water $\left(3.51\right.$.) at $4^{\circ}$ and collected once more.

Washed mycelium (120 g. wet-wt.) was dispersed in the Waring Blendor in icecold 0.1 M-NaCl solution (150 ml.; Crook \& Johnston, 1962), and portions (30-40 ml.) were passed at $16,000 \mathrm{lb}$. $/ \mathrm{in}^{2}$. through a fine needlevalve of a type similar to that described by Milner, Lawrence \& French (1950). The wall fraction was recovered from the suspension of broken hyphae by centrifugation for 10-15 min. at $1400 \mathrm{~g}$, suspended in $\mathrm{M}$-sucrose and collected by centrifugation. Resuspension and centrifugation were repeated twice more with $\mathrm{m}$-sucrose, three times with $0 \cdot 1 \mathrm{M}-\mathrm{NaCl}$ and three times with water, all below $4^{\circ}$. Preparations contained no unbroken hyphae (absence of intense staining with methylene blue $0.01 \%$ ). The yield of wall obtained by freeze-drying the final plug was usually 4-6 g.

\section{Analytical methods}

Analyses of medium constituents and mycelial dry weights were made as previously described (Done et al. 1961).

Total nitrogen was estimated by the micro-Kjeldahl procedure of Chibnall, Rees \& Williams (1943).

Total carbohydrate (bound hexose) was determined by a modification of the orcinol $\mathrm{H}_{2} \mathrm{SO}_{4}$ method of Winzler (François, Marshall \& Neuberger, 1962).

Total hexosamine was quantitatively determined, after hydrolysis of the samples in $4 \mathrm{~N}-\mathrm{HCl}$ for $4 \mathrm{hr}$ at $110^{\circ}$, by the Elson-Morgan reaction (Blix, 1948), with glucosamine as standard.

Lipids were extracted into chloroform + methanol $(2+1$, by vol.), washed with $\mathbf{0} \cdot \mathbf{2}$ vol. water and evaporated to dryness. Analysis of constituent fatty acids after methanolysis (Metcalfe \& Schmitz, 1961) was done on a Pye-Argon Gas Chromatograph (W. G. Pye and Co., Cambridge, England), with Apiezon L or polyethylene glycol adipate as the stationary phase.

$A s h$ was estimated in samples heated at $600^{\circ}$ to constant weight. 
Phosphorus was estimated by the method of Berenblum \& Chain (1938).

Tryptophan was determined on unhydrolysed samples by the method of OpienskaBlauth, Charęziński \& Berbeć (1963).

Paper chromatography was done on Whatman No. 1 paper. The following solvent systems were used: $(A)$ ethyl acetate + pyridine + water $(10+4+3$, by vol. $)$; (B) butan-1-ol + pyridine + water $(6+4+3$, by vol.). Detection methods: for reducing sugars, alkaline silver nitrate (Trevelyan, Procter \& Harrison, 1950) or aniline hydrogen phthalate (Partridge, 1948); and for amino acids, $0.2 \%(\mathrm{w} / \mathrm{v})$ ninhydrin in acetone.

\section{Hydrolysis of hyphal roall}

(1) For monosaccharide constituents, the wall fraction $(5 \mathrm{mg}$.) was suspended in $0.1 \mathrm{ml}$. of $72 \%(\mathrm{v} / \mathrm{v}) \mathrm{H}_{2} \mathrm{SO}_{4}$; after $18 \mathrm{hr}$ at room temperature the solution was diluted with water $\left(0.7 \mathrm{ml}\right.$.), heated at $100^{\circ}$ for $4 \mathrm{hr}$ in a sealed tube, then neutralized (pH 6) with barium carbonate, filtered and the filtrate evaporated to dryness at $\mathbf{2 5 ^ { \circ }}$ under vacuum.

(2) For amino acids, the wall fraction ( $30 \mathrm{mg}$.) was hydrolysed by $6 \mathrm{~N}$-hydrochloric acid $\left(50 \mathrm{ml}\right.$.) at $110^{\circ}$ for $18 \mathrm{hr}$. The hydrolysate was evaporated to dryness under reduced pressure and dried over solid sodium hydroxide. Quantitative analysis of the amino acids was carried out by the method of Spackman, Stein \& Moore (1958) in an Automatic Analyser (Evans Electroselenium Ltd., Halstead, Essex).

(3) For nucleic acids, the wall fraction (10 mg.) was hydrolysed by $\mathrm{N}-\mathrm{HCl}$ for $\mathbf{l ~ h r}$ and the hydrolysate chromatographed in butan-1-ol + acetic acid + water $(4+1+5$, by vol.). The chromatogram was examined in ultraviolet light for the presence of purines and pyrimidines.

\section{RESULTS}

Although no isolate of Pithomyces chartarum tested by Dingley, Done, Taylor \& Russell (1962) formed more than a few conidia in submerged culture it was desirable, for work on hyphal walls, to use an asporogenous isolate. It was also desirable to obviate batch-to-batch variation due to adaptive behaviour of a heterokaryon, by using a homokaryotic strain. Neither ideal was achieved; all the isolates obtained by hyphal-tip subculture sectored under favourable conditions, and none was completely asporogenous. However, the isolate $\mathrm{E}-\mathrm{HT} / \mathbf{1} \mathrm{did}$ not sector on the minimal medium used, and no spores were detected in submerged cultures. This isolate also had the advantage that its walls were only lightly pigmented. Preliminary work with the conidia of $\boldsymbol{P}$. chartarum has shown that characterization of other wall constituents is complicated by the presence of pigment.

Because of the morphological heterogeneity resulting from surface culture, submerged liquid culture was used to produce a homogeneous mycelium free from conidia. Although the organism grew well in shake flasks, a more even and finely divided growth was obtained in a simple fermentor. In Fig. 1 the growth and utilization of medium constituents are shown for a typical culture; the incubation was terminated after 4 days, when the mycelium had become so dense that stirring and aeration were impaired. 


\section{Preparation and analysis of the hyphal wall fraction}

After early experiments on disruption of hyphae with glass beads (Korn \& Northcote, 1960; Crook \& Johnson, 1962) we changed to a method in which the mycelial suspension was passed under pressure through a fine needle-valve. This, followed by differential centrifugation to remove cell contents, gave a cleaner product in higher yield than was obtained by similar treatment of bead-disrupted hyphae. The wall fraction was obtained in larger fragments, up to $20 \mu$ long. No

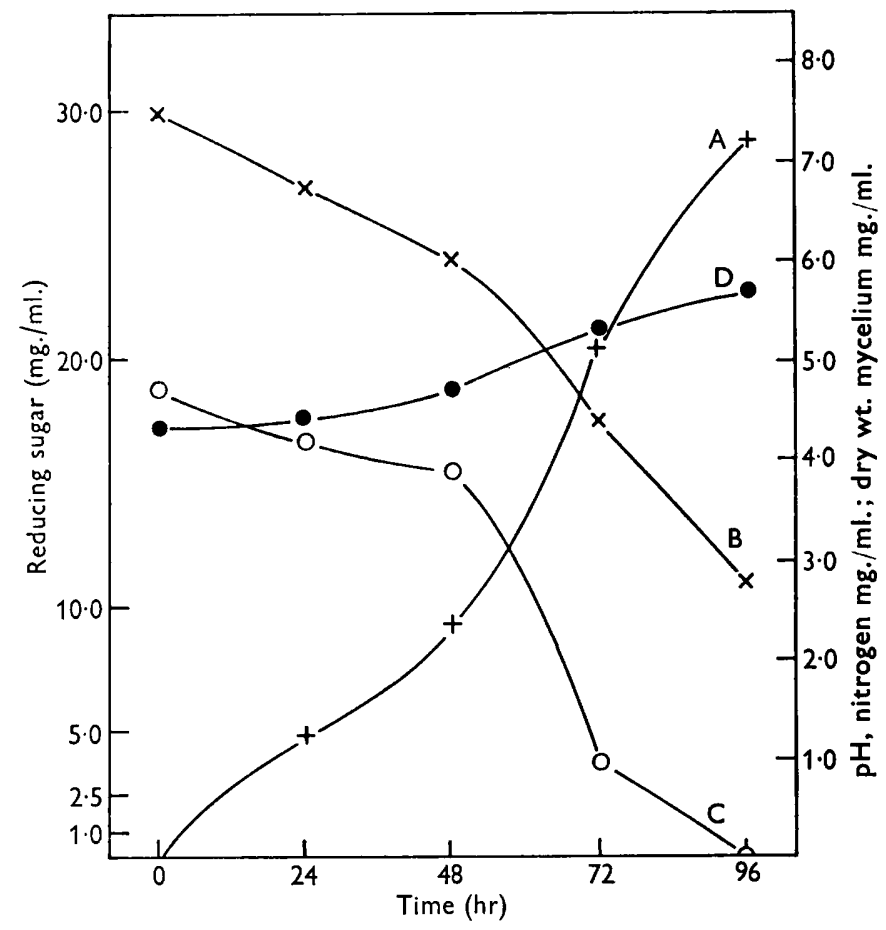

Fig. 1. Growth of Pithomyces chartarum isolate E-HT/1, on defined medium in deep culture at $25^{\circ}$, as a function of culture age. A, Dry-wt. mycelium; B, reducing sugar in culture filtrate; $\mathrm{C}$, nitrogen in culture filtrate; $\mathrm{D}, \mathrm{pH}$ value of medium.

Table 1. Analysis of freeze-dried hyphal wall fraction of Pithomyces chartarum isolate $\mathrm{E}-\mathrm{HT} / 1$

Bound hexose

'Total nitrogen

Bound hexosamine

Protein nitrogen (by difference)*

Protein nitrogen (by amino acid analysis) $\dagger$

Lipid

Phosphorus

Ash

Moisture

\section{$\%$}

$37-41$

$3 \cdot 8-4 \cdot 6$

9-10

$3 \cdot 1-3 \cdot 9$

$2 \cdot 4-2 \cdot 9$

$\mathbf{8} \cdot \mathbf{5}-\mathbf{8} \cdot \mathbf{7}$

$0.5-0.6$

3-5

5-6

* Calculated by subtracting bound hexosamine nitrogen from total nitrogen.

$\dagger$ Calculated by adding together the nitrogen of the amino acids determined by ion-exchange chromatography. 
cytoplasm was detected either in the optical microscope after mounting the material in methylene blue solution, or in electron micrographs (kindly prepared by Dr Hilary Griffiths) of unsectioned fragments fixed with phosphotungstic acid (Plate 1). In Table 1 are listed the results of analyses of many batches of wall fraction prepared in this way. Nucleic acids were not detected.

Samples were hydrolysed by acid and the hydrolysates examined by paper chromatography for the presence of sugars; only hexoses and hexosamine were found. Other hydrolysates were submitted to amino acid analysis by ion-exchange chromatography, kindly carried out by Mr L. Lester. Tryptophan, which is acidlabile, was determined separately. In view of the known mutual destruction of amino acids and sugars during acid hydrolysis, the results, listed in Table 2, are presented only semiquantitatively.

Table 2. Monosaccharide and amino acid composition of acid hydrolysates of hyphal wall fraction of Pithomyces chartarum isolate $\mathbf{E}-\mathbf{H T} / \mathbf{1}$

Constituent
Glucose
Galactose
Mannose
Glucosamine
Aspartic acid
Threonine
Serine
Glutamic acid
Proline
Glycine
Alanine

$$
\begin{gathered}
\text { Amount* } \\
+++++ \\
+ \\
+ \\
++++ \\
\\
++++ \\
++++ \\
+++++ \\
++++ \\
++++ \\
+++++ \\
+++++
\end{gathered}
$$

$\quad$ Constituent
Valine
Methionine
Isoleucine
Leucine
Tyrosine
Phenylalanine
Lysine
Histidine
Arginine
Tryptophan
Cystine+cysteine
Ammonia

$$
\begin{gathered}
\text { Amount } \\
++++ \\
+ \\
++ \\
++++ \\
+ \\
+++ \\
+++ \\
+ \\
+ \\
+ \\
+ \\
++++
\end{gathered}
$$

* For sugars, the size of spots on chromatograms, judged by eye, varied from +++++ (maximum size) to + (small spot). For amino acids, the range in $\mu$ moles $/ \mathrm{mg}$. nitrogen, was $+++++(>2 \cdot 0),++++(1 \cdot 5-2),+++(1-1 \cdot 5),++(0 \cdot 5-1),+(<0 \cdot 5),-$ (not detected).

A small peak on the ion-exchange chromatogram, estimated to be about $0.5 \%$ of the total hexosamine, may have been due to galactosamine. Estimation of galactosamine in the presence of glucosamine becomes inaccurate when the minor component represents less than $2 \%$ of the total hexosamine (Gardell, 1953; Cessi \& Serafini-Cessi, 1962; Johnston, 1963). An artificial mixture of 2.4 mg. glucosamine $+100 \mu \mathrm{g}$. galactosamine was cleanly separated on a column of Zeo-Karb 225 $(60 \times 1 \mathrm{~cm}$.) by the method of Crumpton (1959), but no such evidence was found for the presence of galactosamine in wall hydrolysates containing similar concentrations of glucosamine. We conclude that more than $99 \%$ of the total wall amino sugar was glucosamine. The identity of glucosamine was confirmed by the Morgan \& Elson (1934) reaction, by its position relative to the amino acids on ion-exchange chromatograms, and by its degradative deamination to arabinose (Stoffyn \& Jeanloz, 1954). No evidence was found for the presence of any other hexosamine.

The lipid was not analysed completely. Vapour-phase chromatography of the methyl esters of the constituent fatty acids, kindly carried out by Miss Julia Cullen, showed the presence, in descending order of abundance, of $\mathrm{C}_{16}$-saturated, $\mathrm{C}_{18}$-diand mono-unsaturated, $\mathrm{C}_{18}$-saturated and $\mathrm{C}_{18}$-mono-unsaturated fatty acids. Small unidentified peaks appeared in the $\mathrm{C}_{12}-\mathrm{C}_{14}$ region. 


\section{DISCUSSION}

This paper records the preparation and properties of a fraction obtained by mechanical disruption of Pithomyces chartarum hyphae. In avoiding chemical or enzymic treatment we sought to isolate the 'whole wall'; we are aware that, in so doing, the ideal of 'nothing but the wall' may have eluded us. Nevertheless, the fraction so prepared is reproducible, is obtained in good yield, and corresponds in morphology to what is generally termed cell wall. Having noted the pertinent comments of de Duve (1964), we have called our material the 'hyphal wall fraction'.

Cell walls may vary in composition even when the organism is grown under controlled conditions. For this reason alone, precise quantitative estimates of amino acids and sugars would be of little significance. In fact, the precision obtainable is low, because chemical changes take place during hydrolysis. This limitation is not serious, for careful fractionation gives homogeneous materials, more amenable to chemical study. The results of such studies will be reported elsewhere.

It is a pleasure to thank Mrs Pamela Riches for skilled technical assistance.

\section{REFERENCES}

Berenblum, I. \& Chain, E. (1938). An improved method for the colorimetric determination of phosphate. Biochem. J. 32, 295.

Bertaud, W. S., Morice, I. M., Russell, D. W. \& Taylor, A. (1963). The spore surface in Pithomyces chartarum. J. gen. Microbiol. 32, 385.

Blix, G. (1948). The determination of hexosamines according to Elson and Morgan. Acta chem. scand. 2, 467.

Butler, G. W., Russell, D. W. \& Clarke, R. T. J. (1962). Incorporation of ${ }^{14}$ C-labelled amino acids into sporidesmolide I by Pithomyces chartarum (Sporidesmium bakeri). Biochim. biophys. Acta, 58, 507.

Cessi, C. \& Serafini-Cessi, F. (1962). The determination of D-galactosamine in the presence of D-glucosamine. Biochem. J. 82, $43 \mathrm{P}$.

Chibnale, A. C., Rees, M. W. \& Williams, E. F. (1943). The total nitrogen content of egg albumin and other proteins. Biochem. J. 37, 354.

Crook, E. M. \& Johnston, I. R. (1962). The qualitative analysis of the cell walls of selected species of fungi. Biochem. J. 83, 325.

Crumpton, M. J. (1959). Identification of amino sugars. Biochem. J. 72, 479.

Dingley, J. M. (1962). Pithomyces chartarum, its occurrence, morphology and taxonomy. N.Z. J. agric. Res. 5, 49.

Dingley, J. M., Done, J., Taylor, A. \& Russeli, D. W. (1962). The production of sporidesmin and sporidesmolides by wild isolates of Pithomyces chartarum in surface and in submerged culture. J. gen. Microbiol. 29, 127.

DE Duve, C. (1964). Principles of tissue fractionation. J. theoret. Biol. 6, 33.

Done, J., Mortimer, P. H., Taylor, A. \& Russell, D. W. (1961). The production of sporidesmin and sporidesmolides by Pithomyces chartarum. J. gen. Microbiol. 26, 207.

Ellis, M. B. (1960). Dematiaceous hyphomycetes. 1. Mycol. Papers, no. 76.

François, C., Marshali, R. D. \& Neuberger, A. (1962). Carbohydrates in protein. 4. The determination of mannose in hen's-egg albumin by radioisotope dilution. Biochem. J. 83, 335.

Gardell, S. (1953). Separation on Dowex 50 ion exchange resin of glucosamine and galactosamine and their quantitative determination. Acta chem. scand. 7, 207.

Johnston, I. R. (1963). The determination of galactosamine in the presence of glucosamine. Application to Aspergillus niger cell walls. Biochem. J. 86, 254. 
Korn, E. D. \& Northcote, D. H. (1960). Physical and chemical properties of polysaccharides and glycoproteins of the yeast-cell wall. Biochem. J. 75, 12.

LACEY, M. E. \& GREGORY, P. H. (1962). Occurrence in Britain of the fungus causing facial eczema in sheep. Nature, Lond. 193, 85.

Milner, H. W., Lawrence, N. S. \& French, C. S. (1950). Colloidal dispersion of chloroplast material. Science, 111, 633.

Metcalfe, L. D. \& Schmitz, A. A. (1961). The rapid preparation of fatty acid esters for gas chromatographic analysis. Analyt. Chem. 33, 363.

Morgan, W. T. J. \& Elson, L. A. (1934). A colorimetric method for the determination of $N$-acetylglucosamine and $N$-acetylchondrosamine. Biochem. J. 28, 988.

Opieńska-Blauth, J., Chagrziński, M. \& Berbeć, H. (1963). A new, rapid method of determining tryptophan. Analyt. Biochem. 6, 69.

Partridge, S. M. (1948). Filter paper partition chromatography of sugars. Biochem. $J$. 42, 238.

Partridge, S. M. (1949). Aniline hydrogen phthalate as a spraying reagent for chromatography of sugars. Nature, Lond. 164, 443 .

Ponteconvo, G. (1953). The genetics of Aspergillus nidulans. Adv. Genet. 5, 141.

Ross, D. J. \& Thonnton, R. H. (1962). A study of the physiology of Pithomyces chartarum (Berk. and Curt.) M. B. Ellis. 3. Production of toxin on some laboratory media. N.Z. J.Sci. 5, 165.

Spackman, D. H., Stein, W. H. \& Moore, S. (1958). Automatic recording apparatus for use in the chromatography of amino acids. Analyt. Chem. 30, 1190.

Stoffyn, P. \& Jeanloz, R. W. (1954). Identification of amino sugars by paper chromatography. Archs Biochem. Biophys. 52, 373.

Trevelyan, W. E., Procter, D. P. \& Harrison, J. S. (1950). Detection of sugars on paper chromatograms. Nature, Lond. 166, 444.

\section{EXPLANATION OF PLATE}

Electron micrographs of Pithomyces chartarum hyphae during preparation of the cell wall fraction.

Fig. 1. Hypha after passage through the needle valve but before washing and centrifugation. Note fracture at extreme right.

Fig. 2. Hypha after washing and centrifugation in $\mathrm{M}$-sucrose and $0 \cdot 1 \mathrm{M}$-sodium chloride.

Fig. 3. Hypha after washing and centrifugation in $\mathrm{M}$-sucrose, $0.1 \mathrm{M}$-sodium chloride and water. 
Journal of General Microbiology, Vol. 36, No. 2

Plate 1
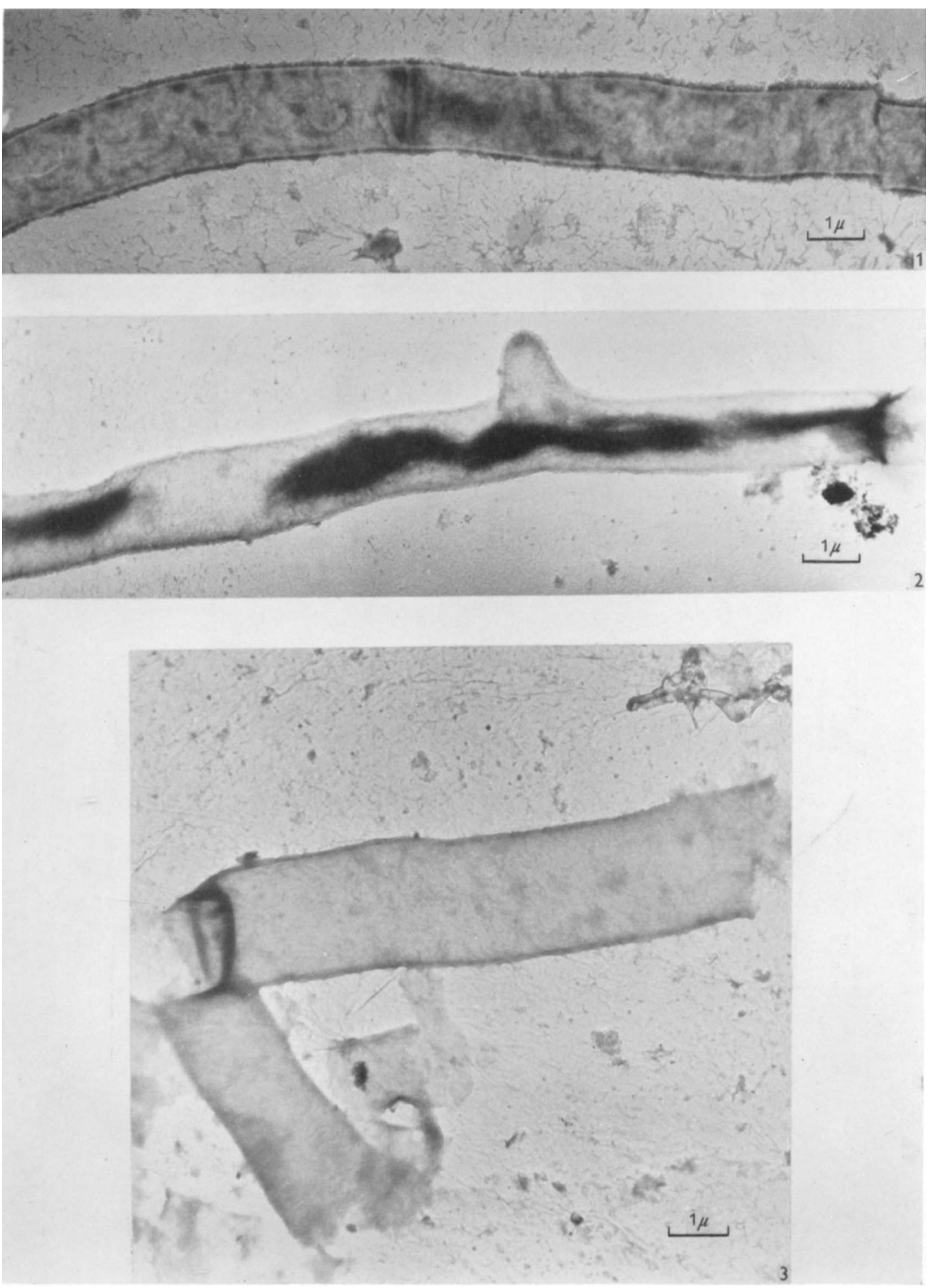